\title{
DIMENSÃO TÉCNICO-OPERATIVA DO TRABALHO DA/O ASSISTENTE SOCIAL NA POLÍTICA URBANA/HABITACIONAL E PROCESSOS PARTICIPATIVOS*
}

\author{
Joana Valente Santana \\ Rita de Cássia Barbosa dos Santos
}

\section{Introdução}

O presente texto tem por objetivo apresentar as requisições profissionais ao trabalho da/o assistente social e as respostas na política urbana e habitacional, dando ênfase aos instrumentos técnico-operativos no exercício profissional, valorizando os processos de participação social/organização política das/os moradores/as nos territórios urbanos.

A/o assistente social trabalha em vários espaços sócio ocupacionais onde chegam demandas da sociedade, demandas estas provenientes das necessidades não atendidas da classe trabalhadora, especialmente as dificuldades para garantia de sua reprodução social. Essas necessidades não atendidas estão articuladas ao conjunto das desigualdades existentes nas sociedades de classes (social, econômica, racial, de gênero.) Em outros termos, a existência de variadas expressões da questão social, racial, patriarcal justificam (especialmente pelo Estado) as requisições profissionais dos assistentes sociais em várias áreas de intervenção por meio das políticas sociais.

O trabalho da/o assistente social na habitação está imerso em determinações contraditórias, próprias da relação capital e trabalho, que particulariza a questão habitacional como uma expressão da questão social, bem como esse trabalho inserese nas contradições entre demandas dos programas habitacionais (via políticas estatais, a exemplo do Programa Minha Casa, Minha Vida) e as demandas da classe trabalhadora. $\mathrm{O}$ trabalho profissional é mediado pelas requisições institucionais e as respostas profissionais orientadas por uma dimensão teórica, metodológica, ética, política, técnica e operativa (Santana, 2020a).

Assim, o presente texto pretende dar luz à dimensão técnico-operativa no exercício profissional na política urbana e habitacional, em articulação com as dimensões teórico-metodológicas e ético-políticas. $O$ texto se propõe a construir um diálogo do fazer profissional da/o assistente social nessas políticas, destacando os instrumentos no trabalho e as potencialidades do incentivo à participação social dos moradores atendidos, propondo outros significados para esta participação entre as requisições e as respostas profissionais.

Vem, entre na experiência do trabalho da/o assistente social na área da habitação, deixe-se tomar pelos seus dilemas, se encante com as suas riquezas, se inspire nas suas resistências!

*DOI - 10.29388/978-65-86678-92-5-0-F.94-112 


\section{De que território estamos falando?}

O Curso de Serviço Social da Universidade Federal do Pará/ UFPA possui uma trajetória de ensino, pesquisa e extensão vinculada à luta pelo direito à cidade, assessoria aos movimentos sociais urbanos e parcerias governamentais no âmbito da política urbana e habitacional. Por exemplo, o Programa (de extensão e pesquisa) de Apoio à Reforma Urbana (PARU/UFPA), institucionalizado em 1992, realizou e ainda realiza diversas atividades voltadas aos interesses da classe trabalhadora, especialmente na Região Metropolitana de Belém.

O grupo de pesquisa do qual é fruto este trabalho ${ }^{1}$, foi criado em 2011, e vem se dedicando ao estudo dos impactos socioeconômicos na vida das famílias que sofrem processos de remoções urbanas (por reassentamento ou remanejamento) por projetos urbanísticos governamentais. Também se dedica ao estudo da questão habitacional em pequenas cidades paraenses (áreas rurais e urbanas), destacando as particularidades do modo de morar na Região Amazônica e a inadequação habitacional por carência de infraestrutura (especialmente a carência de saneamento básico). Na sua trajetória, o grupo foi construindo o interesse em estudar o trabalho profissional da/o assistente social na política urbana e habitacional e as contradições desse trabalho mediadas pelas requisições e as respostas profissionais.

Em setembro de 2019, foi realizado, na cidade de Belém/Pará, o "Seminário Habitação na Amazônia: particularidades e desafios ao trabalho profissional do assistente social" ${ }^{2}$. Definiu-se como principal público-alvo, mas não exclusivamente, as/os assistentes sociais, que trabalham na área urbana e habitacional. Como estratégia de participação, a coordenação do evento enviou Ofício às prefeituras municipais dos 144 municípios do Estado do Pará, para que as/os assistentes sociais pudessem participar do evento, em Belém, com os custos de viagem e hospedagem garantidos pelas Prefeituras ${ }^{3}$.

Participaram do evento 254 pessoas, dentre as quais assistentes sociais que trabalham em diferentes instituições governamentais, não governamentais e privadas, das cidades de Belém, Ananindeua, Cametá, Canaã dos Carajás, Castanhal, Marituba, Macapá, São Miguel do Guamá, São Paulo, Oeiras do Pará, e Vigia. Dos 43 trabalhos apresentados em 5 grupos de trabalho (na modalidade comunicação científica e relatos de experiência), a maioria (23 trabalhos) foi apresentado no eixo que trata-

\footnotetext{
${ }^{1}$ Participam do Grupo docentes de Serviço Social, Geografia e Arquitetura e Urbanismo, pesquisadores da Companhia de Habitação do Estado do Pará e da FASE/Amazônia, discentes de pós-graduação, graduação e iniciação científica, bem como pesquisadores da área do Serviço Social.

${ }^{2}$ O Seminário teve por objetivos: Socializar pesquisas acadêmicas acerca da questão urbana e habitacional na Amazônia; Propiciar o conhecimento e a troca de experiências profissionais sobre o trabalho profissional nas políticas urbanas e habitacionais na Amazônia; Fortalecer a discussão de estratégias de organização coletiva e participação política no trabalho profissional; Estimular a reflexão teórico-metodológica de profissionais que trabalham na área urbana e habitacional, bem como estudantes de graduação e pós-graduação; Contribuir com a melhoria das condições de vida nas cidades amazônicas.

${ }^{3}$ Durante o Seminário foi lançada a Coletânea de Textos: "Habitação e Serviço Social: dimensões teóricas, históricas e metodológicas", organizada por Joana Valente Santana, 2018, Editora: Papel Social (Campinas/SP). A coletânea possui 13 artigos distribuídos em 4 partes: "Fundamentos do trabalho profissional do assistente social: questões agrária, urbana e ambiental", "Serviço Social nos diferentes momentos históricos da política habitacional brasileira", "Trabalho profissional do assistente social em políticas urbanas e habitacionais: reflexões teóricas e discussão de experiências" e "Resistências pelo direito à cidade e desafios ao Serviço Social".
} 
va do Serviço Social e política urbana e habitacional. Durante o Seminário os assistentes sociais falaram de seu contentamento em ter um espaço dentro da Universidade para apresentar os dilemas de seu trabalho no cotidiano da profissão. O resultado dessa troca foi a criação de um Fórum de Trabalho Social no Pará, coordenado pelos grupos de pesquisa e extensão mencionados (GEP-CIHAB, PARU/UFPA).

A pandemia do novo coronavírus (desde março de 2020) dificultou os trabalhos do referido Fórum. Como forma de manter um diálogo com os assistentes sociais, o GEP-CIHAB organizou uma live intitulada "O trabalho do/a Assistente Social na Política Urbana/Habitacional", em outubro de 2020, com destaque para a dimensão técnico - operativa e os desafios do trabalho da/o assistente social na habitação na conjuntura de crise econômica, política e sanitária. Como estratégia de aproximação às/aos profissionais, o Grupo - além da divulgação nas redes sociais enviou convite específico a todas/as as/os assistentes sociais que participaram do Seminário Habitação na Amazônia (citado anteriormente) ${ }^{4}$.

Atualmente o grupo vem desenvolvendo o projeto de pesquisa, financiado pelo Conselho Nacional de Desenvolvimento Científico e Tecnológico/CNPq, "Serviço Social e remoção de moradores atingidos por projetos urbanísticos no Brasil: requisições e respostas profissionais", que tem por objetivo evidenciar o trabalho profissional das/os assistentes sociais em projetos urbanísticos que envolvem processos de remoção de moradores, verificando as demandas, respostas e estratégias profissionais nesses processos, articuladas ao projeto ético-político da profissão.

Os estudos, as aproximações e as trocas com as/os assistentes sociais em seu cotidiano profissional nos levaram a perguntar sobre as particularidades do fazer profissional do assistente social na política urbana e habitacional, quais as principais requisições, respostas e estratégias possíveis que esses profissionais podem desenvolver, considerando as contradições inerentes às requisições institucionais do Estado capitalista, mediado por essas políticas, mas também construindo resistências no cotidiano profissional, dando ênfase aos instrumentos e técnicas, que são constituintes da dimensão técnico operativas da formação e exercício profissional.

Na próxima seção, faremos uma discussão teórica sobre as formulações que orientam a formação profissional em Serviço Social acerca das dimensões teóricometodológicas, ético-políticas e técnico-operativas, apontando que essa última dimensão tem sido pouco estudada pelo Serviço Social brasileiro.

\section{Para iluminar a reflexão}

As Diretrizes Curriculares para os cursos de Serviço Social definiram como competências e habilidades gerais que a formação profissional da/o assistente social "deve viabilizar uma capacitação teórico-metodológica e ético-política, como requisito fundamental para o exercício de atividades técnico-operativas", que devem permitir ao profissional a apreensão do "significado social da profissão e de seu desenvolvimento sócio-histórico [...] desvelando as possibilidades de ação contidas na realida-

\footnotetext{
${ }^{4}$ As palestrantes foram: Raquel Paiva Gomes (UFABC) estudiosa do tema do trabalho social na habitação e Erica Laiana Lobato da Silva, Assistente Social no Setor de Habitação, na Prefeitura Municipal de Abaetetuba//Pará. A live foi mediada por Rita de Cássia Barbosa dos Santos.
} 
de", identificando demandas existentes na realidade para a formulação de "respostas profissionais para o enfrentamento da questão social [...]" (Brasil, 2002, p. 01).

Essas diretrizes foram amplamente discutidas nos fóruns da categoria profissional capitaneadas pela então Associação Brasileira de Ensino de Serviço Social/ABESS (hoje Associação Brasileira de Ensino e Pesquisa em Serviço Social/ABEPSS), na década de $1990^{5}$.

As referidas Diretrizes curriculares propõem uma articulação entre a capacitação teórico-metodológica, ético-política e técnico-operativa (ABESS/CEDEPSS, 1997) como uma unidade indissociável nos processos formativos das/os assistentes sociais. Entretanto, as mediações entre essas dimensões se caracterizam como um desafio no âmbito do Serviço Social brasileiro. Há uma recorrência entre os profissionais de que os componentes dos projetos pedagógicos na graduação não são facilmente traduzidos para o exercício profissional. Por esse motivo, persiste, conforme Santos (2010) e Forti e Guerra (2010) a corriqueira afirmação, que "na prática, a teoria é outra".

Não é objetivo deste texto apresentar essa complexa discussão, mas é possível afirmar que a dimensão interventiva da profissão tem tido menor evidência na produção e debate da categoria. Nesta direção, Guerra (s.d, p. 3) afirma que "apesar da sua relevância, a tematização da dimensão técnico-operativa tem sido negligenciada pela atual produção acadêmica, pela formação profissional e pelo debate da categoria" ${ }^{\prime 6}$. Nessa mesma direção, afirmam Mioto e Lima (2009, p. 28):

Nessa condição é que se busca delinear a questão da dimensão técnico-operativa. A partir de algumas observações realizadas nos campos da produção bibliográfica e do exercício e da formação profissional, é possível constatar que o debate em torno da operatividade do Serviço Social tem se caracterizado pela escassez, quando comparado às dimensões teórico-metodológicas e éticopolíticas, e sobre o próprio campo de incidência do Serviço Social (as políticas sociais e os direitos de forma geral) (lamamoto, 1999; Simionato, 2004). Além disso, importantes estudos sobre o exercício profissional demonstram a sua desconexão com o atual projeto profissional.

Ao mesmo tempo em que essas afirmações nos parecem corretas, é importante considerar que, no conjunto das discussões dos fóruns da categoria profissional e das produções acadêmicas, há um forte avanço nos estudos anunciados pela orientação teórico-metodológica marxiana que se voltam a problematizar as contradições sociais e econômicas inerentes à sociabilidade

\footnotetext{
${ }^{5}$ Dentre os princípios orientadores da formação profissional, discutidos pela Associação, destacam-se: “(...) rigoroso trato teórico, histórico e metodológico da realidade social e do Serviço Social, que possibilite a compreensão dos problemas e desafios com os quais o profissional se defronta no universo da produção e reprodução da vida social; (...) estabelecimento das dimensões investigativa e interventiva como princípios formativos e condição central da formação profissional e da relação teoria e realidade". (ABESS/CEDEPSS, 1997, p. 61).

${ }^{6}$ Em pesquisa sobre a produção no Serviço Social, Santos e Noronha (2010, p. 51) afirmam que: “(...) é reduzido o número de fontes pesquisadas no período de 1990 a 2008 que abordam a questão dos instrumentos. Porém mais reduzido ainda é o número daquelas que descrevem os tipos de instrumentos utilizados no serviço social."
} 
burguesa, notadamente as desigualdades de classe e todas as formas de dominação (como raça e gênero) e vem, afirmando um projeto profissional ético e político que defende radicalmente os direitos humanos, a democracia, os direitos sociais, a liberdade, o direito à diferença entre as pessoas, sintetizadas na defesa da emancipação humana em sua forma mais complexa.

Diante disso, é possível afirmar que daquelas dimensões (antes aludidas) definidas nas Diretrizes Curriculares, o Serviço Social brasileiro avançou significativamente - mesmo que com concepções diferenciadas - nas discussões dos fundamentos relativos às dimensões teórico-metodológicas e ético-políticas. Se isso é verdade, parece que um dos desafios do Serviço Social é equilibrar os pesos entre as dimensões ${ }^{7}$ construídas nas referidas Diretrizes, isto é, problematizar, interpretar e ampliar o interesse à dimensão técnico-operativa da profissão, como unidade contraditória e indissociável das demais dimensões constituintes e constitutivas da profissão (as dimensões teórico-metodológicas e ético-políticas). Conforme afirma Santos (2013, p. 2).

Sinteticamente, podemos afirmar que a relação entre as dimensões se coloca no exercício profissional da seguinte forma: teoria como instrumento de análise do real, onde ocorre a intervenção profissional (dimensão teórico-metodológica) para criar estratégias e táticas de intervenção (dimensão técnico-operativa), comprometidas com um determinado projeto profissional (dimensão ético-política).

De acordo com Santos e Noronha (2010), os instrumentos e técnicas da intervenção profissional são um dos elementos constitutivos da dimensão técnicooperativa do Serviço Social, que se vincula às demais (teórico-metodológica e éticopolítica) através de uma relação de unidade na diversidade. Ao analisar a dimensão técnico-operativa do Serviço Social, Sarmento (2017, p. 117 -118) afirma que:

Técnica é um reconhecimento empírico, elaborado, desenvolvido pela capacidade humana como prolongamento de sua racionalidade para realizar coisas. [...] Entendendo a técnica como criação, enquanto desdobramento da racionalidade, verifico que neste processo de trabalho humano a consciência tem participação ativa, uma vez que elabora finalidades e produz conhecimentos orientando as ações e se constituindo nelas.

Ao compreender as diferentes estratégias construídas pela/o assistente social no cotidiano profissional se reconhece que os instrumentos e técnicas é que permitem a "operacionalização das propostas de ação conscientemente definidas" (Sarmento, 2017, p. 118). Para o autor:

\footnotetext{
7 De acordo com Santos (2013, p. 25) “(...) a intervenção profissional do assistente social é constitutiva de diferentes dimensões, dentre elas, as dimensões teórico-metodológica, ético-política e técnico-operativa; (...) essas dimensões constituem uma relação de unidade na diversidade; (...) a dimensão técnico-operativa do Serviço Social expressa as demais dimensões; (...) os instrumentos e técnicas são um dos elementos constitutivos da dimensão técnico operativa."
} 
É neste complexo conjunto de relações que os instrumentos se constituem e se apresentam como potencializadores das intencionalidades teórico-políticas do profissional para a efetivação da ação, e as técnicas se constituem nas maneiras através das quais ele conduz suas ações ou objetiva suas intencionalidades (Sarmento, 2017, p. 118).

Assim, considerar a dimensão técnico-operativa é compreender a intencionalidade, a intervenção na realidade e, sobretudo, os resultados alcançados. Portanto, os instrumentais não são meros modelos, documentos, manuais que operacionalizam o trabalho da/o Assistente Social, são elementos que constituem o modo de ser da profissão, sendo assim "mediações através das quais o assistente social objetiva seus projetos, ou seja, 'lança mão' destes para a efetivação da ação" (Sarmento, 2017, p. 118).

Como forma de contribuir com essas reflexões, para efeito deste capítulo, foi realizado um levantamento, no período de 2013 a 2019, para identificar o número de trabalhos de conclusão (mestrado e doutorado), estudos estes defendidos nos programas de pós-graduação em Serviço Social ${ }^{8}$, sendo encontrado um total de 3.738. Após, foi levantada a incidência do estudo sobre a Dimensão Técnico Operativa, neste mesmo período, no Catálogo de Teses e Dissertações da Coordenação de Aperfeiçoamento de Pessoal de Nível Superior/CAPES ${ }^{9}$, na produção discente dos Programas de Pós-Graduação da Área de Serviço Social ${ }^{10}$, o levantamento identificou que em apenas 19 trabalhos o termo de busca "Dimensão técnico-operativa" aparece como resultado, o equivalente a 0,5\%, o que é bastante residual na totalidade dos trabalhos de conclusão dos PPGs da área.

Também foi realizado um levantamento no Portal de Periódicos da Capes ${ }^{11}$ utilizando-se o recurso de pesquisa simples, sem recorte temporal, com seleção de periódicos revisados por pares, em língua portuguesa. Foi encontrado apenas 01 (um) artigo em cujo título encontra-se o termo de busca "dimensão técnicooperativa"12. Neste sentido, Sarmento (2017, p. 109-110) destaca:

Também é interessante destacar, neste introito, o constante "apelo" por "respostas" acerca dessa dimensão interventiva por parte de estudantes de graduação, pós-graduação e de profissionais que estão atuando na área do Serviço Social. Isso sinaliza que ainda é uma discussão teórica e prática em aberto, rica de possibilidades, dicotomias e contradições, mas que precisa

\footnotetext{
${ }^{8}$ Plataforma Sucupira (https://sucupira.capes.gov.br/sucupira) Relatórios dos PPG's em Serviço Social (2013 a 2019).

${ }^{9}$ Catálogo de Teses e Dissertações da Capes. Disponível em: https://catalogodeteses.capes.gov.br. Acesso em 20 out. 2020. Termo de busca: Dimensão técnico-operativa. Critérios de inclusão: área de Serviço Social; período: 2013 a 2019.

${ }^{10}$ Atualmente existem 36 PPGs na área de Serviço Social, aprovados (e em funcionamento) na Capes.

${ }^{11} \mathrm{https}$ ://www.periodicos.capes.gov.br/. Levantamento realizado em 21 out. 2020.

${ }^{12}$ A saber, Mioto e Lima (2009). Vale registrar que em pesquisa livre no google foi encontrado o texto: TRINDADE, R. L. P. Desvendando as determinações sócio históricas do instrumental técnico-operativo do Serviço Social na articulação entre demandas sociais e projetos profissionais. Temporalis, Rio de Janeiro, v. 1, n.4, p. 21-42, 2001. Brasília: ABEPSS.
} 
receber um tratamento investigativo e produtivo para que não seja desqualificada por princípio.

Nos levantamentos antes aludidos, não foi possível identificar nenhum trabalho que tenha tratado do tema da dimensão técnico-operativa do trabalho profissional na área da habitação. Na seção seguinte, apresentaremos uma síntese dos principais instrumentos utilizados no exercício profissional da/o assistente social na política urbana e habitacional.

\section{Adapte, use e reutilize: Principais instrumentos utilizados na intervenção profissional na política urbana e habitacional}

Nesta seção, apresentamos uma síntese das principais requisições e respostas profissionais do Serviço Social em diferentes momentos históricos, de acordo com o contexto da política urbana/habitacional brasileira, destacando os principais instrumentos utilizados no fazer profissional.

Quadro 1 - Requisições, respostas e principais instrumentos utilizados no fazer profissional do Assistente Social na política urbana e habitacional em diferentes conjunturas históricas no Brasil

\begin{tabular}{|c|c|c|c|c|}
\hline $\begin{array}{l}\text { Período } \\
\text { Histórico }\end{array}$ & $\begin{array}{l}\text { Contexto da } \\
\text { política }\end{array}$ & $\begin{array}{l}\text { Principais } \\
\text { requisições }\end{array}$ & $\begin{array}{c}\text { Respostas } \\
\text { profissionais }\end{array}$ & $\begin{array}{c}\text { Principais } \\
\text { instrumentos } \\
\text { utilizados no } \\
\text { fazer } \\
\text { profissional }\end{array}$ \\
\hline $\begin{array}{l}\text { Regime militar } \\
\text { (Décadas: } 1960 \\
\text { a 1980). }\end{array}$ & $\begin{array}{l}\text { Sistema Financeiro } \\
\text { de Habitação / Ban- } \\
\text { co Nacional de Ha- } \\
\text { bitação/ Companhi- } \\
\text { as de Habitação } \\
\text { (COHABs). }\end{array}$ & $\begin{array}{l}\text {-1964: No contexto } \\
\text { da construção dos } \\
\text { conjuntos habitacio- } \\
\text { nais: } \\
\text { a) Seleção de de- } \\
\text { manda (futuros mo- } \\
\text { radores) dos em- } \\
\text { preendimentos ha- } \\
\text { bitacionais; } \\
\text { b) Controle de ina- } \\
\text { dimplência; } \\
\text { c) Promoção da par- } \\
\text { ticipação dos mu- } \\
\text { tuários / direitos e } \\
\text { deveres dos cida- } \\
\text { dãos. } \\
\text { - 1970: No contexto } \\
\text { urbanização de fave- } \\
\text { las, auto construção, } \\
\text { regularização de lo- } \\
\text { tes: } \\
\text { a) Apresentação dos } \\
\text { projetos aos mora- } \\
\text { dores especialmente }\end{array}$ & $\begin{array}{l}\text { Estratégias de } \\
\text { atendimentos } \\
\text { para a seleção } \\
\text { da demanda. }\end{array}$ & $\begin{array}{l}\text { Entrevista } \\
\text { Atendimento } \\
\text { Reunião }\end{array}$ \\
\hline
\end{tabular}




\begin{tabular}{|c|c|c|c|c|}
\hline & & $\begin{array}{l}\text { as remoções); } \\
\text { b) Discussão sobre } \\
\text { equipamentos co- } \\
\text { munitários (água es- } \\
\text { goto e coleta de } \\
\text { lixo); } \\
\text { c) Projetos de gera- } \\
\text { ção de trabalho e } \\
\text { renda. (Paz, et al). } \\
\text { 2018). }\end{array}$ & & \\
\hline $\begin{array}{l}\text { Abertura demo- } \\
\text { crática (Finais da } \\
\text { década de 1980, } \\
1990 \text { e início da } \\
\text { década 2000). }\end{array}$ & $\begin{array}{l}\text { Experiências de ges- } \\
\text { tão democrática da } \\
\text { cidade. } \\
\text { Constituição Federal } \\
\text { de } 1988 \text { (Artigos } \\
182 \text { e 183) } \\
\text { Planos Diretores ur- } \\
\text { banos. } \\
\text { Contexto do movi- } \\
\text { mento de Reforma } \\
\text { Urbana. }\end{array}$ & $\begin{array}{l}\text { - Elaboração de pro- } \\
\text { jetos Técnico sociais } \\
\text { tomando como eixo } \\
\text { a organização comu- } \\
\text { nitária de base de- } \\
\text { mocrática; } \\
\text { - Assessoria a movi- } \\
\text { mentos sociais. }\end{array}$ & 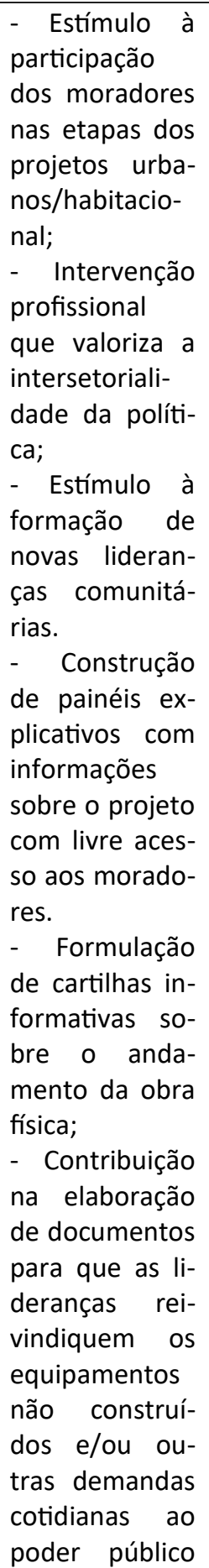 & $\begin{array}{l}\text { - Reuniões por } \\
\text { rua } \\
\text { - Reuniões por } \\
\text { quadras } \\
\text {-Reuniões entre } \\
\text { os profissionais } \\
\text { de diferentes } \\
\text { áreas (Serviço } \\
\text { Social, Arquite- } \\
\text { tura e urbanis- } \\
\text { mo e Engenharia } \\
\text { Civil) } \\
\text { - Informação } \\
\text { através de ma- } \\
\text { teriais diversos, } \\
\text { tais como carti- } \\
\text { lhas, oficinas. }\end{array}$ \\
\hline
\end{tabular}




\begin{tabular}{|c|c|c|c|c|}
\hline & & & $\begin{array}{l}\text { (Perdigão; San- } \\
\text { tana, 2018). }\end{array}$ & \\
\hline $\begin{array}{l}\text { Período após } \\
\text { Constituição, } \\
\text { que coexiste } \\
\text { com o início da } \\
\text { implementação } \\
\text { do Neoliberalis- } \\
\text { mo no Brasil } \\
\text { (Década 1990). }\end{array}$ & $\begin{array}{l}\text { Programa } \\
\text { Habitar Brasil/BID/ } \\
\text { HBB } \\
\text { - Pro-Moradia } \\
\text { - Programa de Ar- } \\
\text { rendamento Resi- } \\
\text { dencial /PAR. }\end{array}$ & $\begin{array}{l}\text { A partir de 1999, o } \\
\text { Trabalho Social é } \\
\text { uma exigência no } \\
\text { contexto do Progra- } \\
\text { ma HBB } \\
\text { - Projeto social de- } \\
\text { veria ser articulado } \\
\text { ao projeto físico. } \\
\text { - Trabalho Social } \\
\text { como um conjunto } \\
\text { de ações para pro- } \\
\text { mover a mobilização } \\
\text { e organização comu- } \\
\text { nitária; educação sa- } \\
\text { nitária e ambiental; } \\
\text { capacitação para ge- } \\
\text { ração de trabalho e } \\
\text { renda; } \\
\text { - Assinatura de ter- } \\
\text { mo de adesão de fa- } \\
\text { mílias; } \\
\text { - Diagnóstico Social } \\
\text { - Plano de Reassen- } \\
\text { tamento das famílias } \\
\text { discutido e aprova- } \\
\text { do com os morado- } \\
\text { res; } \\
\text { - Cadastro de famí- } \\
\text { lias (Paz, et. al, } \\
\text { 2018). } \\
\text {-Atuação nas estra- } \\
\text { tégias do orçamento } \\
\text { participativo experi- } \\
\text { mentado pelo muni- } \\
\text { cípio de Belém/Pa. } \\
\text {-Criação de estraté- } \\
\text { gias para a participa- } \\
\text { ção ampliada da po- } \\
\text { pulação no âmbito } \\
\text { das políticas públi- } \\
\text { cas. }\end{array}$ & $\begin{array}{l}\text { - Trabalho pro- } \\
\text { fissional do as- } \\
\text { sistente social } \\
\text { articulado ao } \\
\text { trabalho de ou- } \\
\text { tros profissio- } \\
\text { nais como en- } \\
\text { genheiros e ar- } \\
\text { quitetos e ur- } \\
\text { banistas (inter- } \\
\text { disciplinarida- } \\
\text { de); } \\
\text { - Trabalho Soci- } \\
\text { al na habitação } \\
\text { articulado a a } \\
\text { outras políticas } \\
\text { como sanea- } \\
\text { mento ambien- } \\
\text { tal, assistência } \\
\text { social, educa- } \\
\text { ção } \\
\text { (Intersetoriali- } \\
\text { dade na políti- } \\
\text { ca); } \\
\text { - Participação } \\
\text { social no pro- } \\
\text { cesso de plane- } \\
\text { amento das ati- } \\
\text { vidades, envol- } \\
\text { vendo morado- } \\
\text { res para levan- } \\
\text { tamento dos } \\
\text { dados da área; } \\
\text { mapeamento } \\
\text { de lideranças } \\
\text { comunitárias } \\
\text { etc.; } \\
\text { - Formação de } \\
\text { um conselho } \\
\text { de controle so- } \\
\text { cial (de caráter } \\
\text { consultivo); } \\
\text { - Organização } \\
\text { de comissões } \\
\text { de obras e ser- } \\
\text { viços; } \\
\text { - Solicitação } \\
\text { dos moradores } \\
\text { para assinatura } \\
\text { do Termo de } \\
\text { Adesão ao pro- } \\
\text { jeto, discutindo }\end{array}$ & $\begin{array}{l}\text { - Visitas domici- } \\
\text { liares; } \\
\text { - Oficinas de } \\
\text { consultas por } \\
\text { ruas e quadras; } \\
\text { - Realização de } \\
\text { rua de lazer; } \\
\text { - Mutirões de } \\
\text { limpeza; } \\
\text { Reuniões com } \\
\text { moradores; } \\
\text { - Realização de } \\
\text { assembleias; } \\
\text { - Estímulo para } \\
\text { funcionamento } \\
\text { dos conselhos } \\
\text { de moradores e } \\
\text { das comissões } \\
\text { de obras e servi- } \\
\text { ços; } \\
\text { - Informações } \\
\text { técnicas do pro- } \\
\text { jeto disponíveis } \\
\text { para os morado- } \\
\text { res (Santana, } \\
\text { 2013). }\end{array}$ \\
\hline
\end{tabular}




\begin{tabular}{|c|c|c|c|c|}
\hline & & & $\begin{array}{l}\text { o termo com } \\
\text { os moradores e } \\
\text { fomentando a } \\
\text { participação } \\
\text { social. (Santa- } \\
\text { na, 2013) }\end{array}$ & \\
\hline $\begin{array}{l}\text { Neoliberalismo } \\
\text { Década } \\
\text { 2000/2010). }\end{array}$ & $\begin{array}{l}\text { Ministério das Cida- } \\
\text { des/Conselho das } \\
\text { Cidades/Política Na- } \\
\text { cional de Habitação } \\
\text { Sistema Nacional de } \\
\text { Habitação de Inte- } \\
\text { resse Social/ SNHIS } \\
\text { Fundo Nacional de } \\
\text { Habitação de Inte- } \\
\text { resse Social/ } \\
\text { FNHIS } \\
\text { Planos Locais de Ha- } \\
\text { bitação de Interesse } \\
\text { Social/PLHIS } \\
\text { Programa Minha } \\
\text { Casa Minha Vida/ } \\
\text { PMCMV } \\
\text { Programa de Acele- } \\
\text { ração de Crescimen- } \\
\text { to/ } \\
\text { PAC. }\end{array}$ & $\begin{array}{l}\text { Instrução Normativa } \\
\text { n. 08/2009 (Ministé- } \\
\text { rio das Cidades). } \\
\text { Trabalho Social: con- } \\
\text { junto de ações que } \\
\text { visam promover a } \\
\text { autonomia, o prota- } \\
\text { gonismo social e o } \\
\text { desenvolvimento da } \\
\text { população, median- } \\
\text { te atividades de mo- } \\
\text { bilização e organiza- } \\
\text { ção comunitária, } \\
\text { educação sanitária e } \\
\text { ambiental e geração } \\
\text { de trabalho e renda. } \\
\text { (Brasil, 2009) } \\
\text { Portaria n. } 21 \text { (de } \\
\text { 22/01.2014): Define } \\
\text { o Manual de Instru- } \\
\text { ções do Trabalho So- } \\
\text { cial dos Programas } \\
\text { do Ministério das Ci- } \\
\text { dades. Trabalho So- } \\
\text { cial: conjunto de es- } \\
\text { tratégias, processos } \\
\text { e ações por meio de } \\
\text { estudos diagnósticos } \\
\text { integrados e partici- } \\
\text { mentos Sociais } \\
\text { - Adequar às famílias } \\
\text { a nova condição de } \\
\text { visando o exercício } \\
\text { da participação e in- } \\
\text { serção social das fa- } \\
\text { mílias, articuladas às } \\
\text { demais políticas, } \\
\text { que se voltem à me- } \\
\text { lhoria da qualidade } \\
\text { de vida, a sustenta- } \\
\text { bilidade dos bens, } \\
\text { equipamentos e ser- } \\
\text { viçantados. }\end{array}$ & $\begin{array}{l}\text { Reuniões com } \\
\text { as famílias para } \\
\text { informações } \\
\text { sobre projetos } \\
\text { urbanísticos; } \\
\text { Apoio à forma- } \\
\text { ção de lideran- } \\
\text { ças comunitá- } \\
\text { rias; } \\
\text { Atividades de } \\
\text { capacitação } \\
\text { profissional } \\
\text { para geração } \\
\text { de renda, bem } \\
\text { como relacio- } \\
\text { nada a educa- } \\
\text { ção ambiental. } \\
\text { Atendimento } \\
\text { das famílias be- } \\
\text { neficiadas e/ou } \\
\text { impactadas } \\
\text { com as obras. }\end{array}$ & $\begin{array}{l}\text { Reuniões } \\
\text { Plantão social } \\
\text { Triagem de de- } \\
\text { mandas } \\
\text { Encaminhamen- } \\
\text { to às redes de } \\
\text { atendimento so- } \\
\text { cioassistencial e } \\
\text { das demais po- } \\
\text { líticas públicas e } \\
\text { órgãos de garan- } \\
\text { tia e defesa de } \\
\text { direitos. } \\
\text { Diagnóstico (Le- } \\
\text { vantamento de } \\
\text { demandas) } \\
\text { Entrevista } \\
\text { Visita domiciliar } \\
\text { Observação da } \\
\text { situação socioe- } \\
\text { conômica das fa- } \\
\text { mílias) } \\
\text { Cadastramento } \\
\text { socioeconômico } \\
\text { Materiais socio- } \\
\text { educativos } \\
\text { Relatórios (San- } \\
\text { tana, 2020b). }\end{array}$ \\
\hline
\end{tabular}




\begin{tabular}{|c|c|c|c|}
\hline & $\begin{array}{l}\text { moradia, promoven- } \\
\text { do o enquadramen- } \\
\text { to do sujeito nas re- } \\
\text { lações presente na- } \\
\text { quele território. (Paz } \\
\text { et al. 2018). }\end{array}$ & & \\
\hline $\begin{array}{l}\text { Ultra neolibera- } \\
\text { lismo (2016 - ). }\end{array}$ & $\begin{array}{l}\text { Portaria № 464, de } \\
25 \text { de julho de } 2018 . \\
\text { Dispõe sobre Traba- } \\
\text { Iho Social nos Pro- } \\
\text { gramas e Ações do } \\
\text { Ministério das Cida- } \\
\text { des- PAC/PMCMV. } \\
\text { Eixos de orientação } \\
\text { do Trabalho Social: } \\
\text { a) Mobilização, or- } \\
\text { ganização e fortale- } \\
\text { cimento social: b) } \\
\text { Acompanhamento e } \\
\text { gestão social da in- } \\
\text { tervenção; c) Educa- } \\
\text { ção ambiental e pa- } \\
\text { trimonial; d) Desen- } \\
\text { volvimento socioe- } \\
\text { conômico (Brasil, } \\
2018, \text { p. 04) } \\
\text { Acompanhar a im- } \\
\text { plantação da gestão } \\
\text { condominial quando } \\
\text { for o caso; } \\
\text { Encaminhamento } \\
\text { para as demais po- } \\
\text { líticas públicas; } \\
\text { Identificação das de- } \\
\text { mandas imediatas } \\
\text { dos beneficiários; } \\
\text { Identificação da } \\
\text { rede de serviços do } \\
\text { entorno do em- } \\
\text { preendimento. }\end{array}$ & $\begin{array}{l}\text { No eixo Mobili- } \\
\text { zação, organi- } \\
\text { zação e fortale- } \\
\text { cimento social; } \\
\text { - Palestras para } \\
\text { socialização de } \\
\text { informações } \\
\text { sobre o Progra- } \\
\text { ma a ser imple- } \\
\text { mentado } \\
\text { (Exemplo de } \\
\text { conteúdo: cri- } \\
\text { térios de parti- } \\
\text { cipação e con- } \\
\text { dições contra- } \\
\text { tuais, entrega } \\
\text { de imóveis, } \\
\text { oferta e locali- } \\
\text { zação de servi- } \\
\text { ços públicos da } \\
\text { área; acesso às } \\
\text { tarifas sociais. } \\
\text { - Palestras so- } \\
\text { bre direitos so- } \\
\text { ciais e orienta- } \\
\text { ção para cria- } \\
\text { ção de associa- } \\
\text { ção de mora- } \\
\text { dores, incluin- } \\
\text { do elaboração } \\
\text { do Estatuto So- } \\
\text { cial das entida- } \\
\text { des dos benefi- } \\
\text { ciários. } \\
\text { - Apoio à Co- } \\
\text { missão de } \\
\text { Acompanha- } \\
\text { mento de de } \\
\text { Obras } \\
\text {-Apoio à for- } \\
\text { mação de lide- } \\
\text { ranças comuni- } \\
\text { tárias; } \\
\text { papacisitaç̧ãonal de } \\
\text { para renda } \\
\text { de renda }\end{array}$ & $\begin{array}{l}\text { Reuniões, como } \\
\text { as realizadas } \\
\text { com as famílias } \\
\text { para informa- } \\
\text { ções sobre pro- } \\
\text { jetos urbanísti- } \\
\text { cos; } \\
\text { Plantão social } \\
\text { Triagem de de- } \\
\text { mandas Encami- } \\
\text { nhamento às re- } \\
\text { des de atendi- } \\
\text { mento socioas- } \\
\text { sistencial, } \\
\text { Diagnóstico (Le- } \\
\text { vantamento de } \\
\text { demandas) } \\
\text { Entrevista } \\
\text { Visita domiciliar } \\
\text { Observação da } \\
\text { situação socioe- } \\
\text { conômica das fa- } \\
\text { mílias) } \\
\text { Cadastramento } \\
\text { socioeconômico } \\
\text { Informações aos } \\
\text { moradores. }\end{array}$ \\
\hline
\end{tabular}




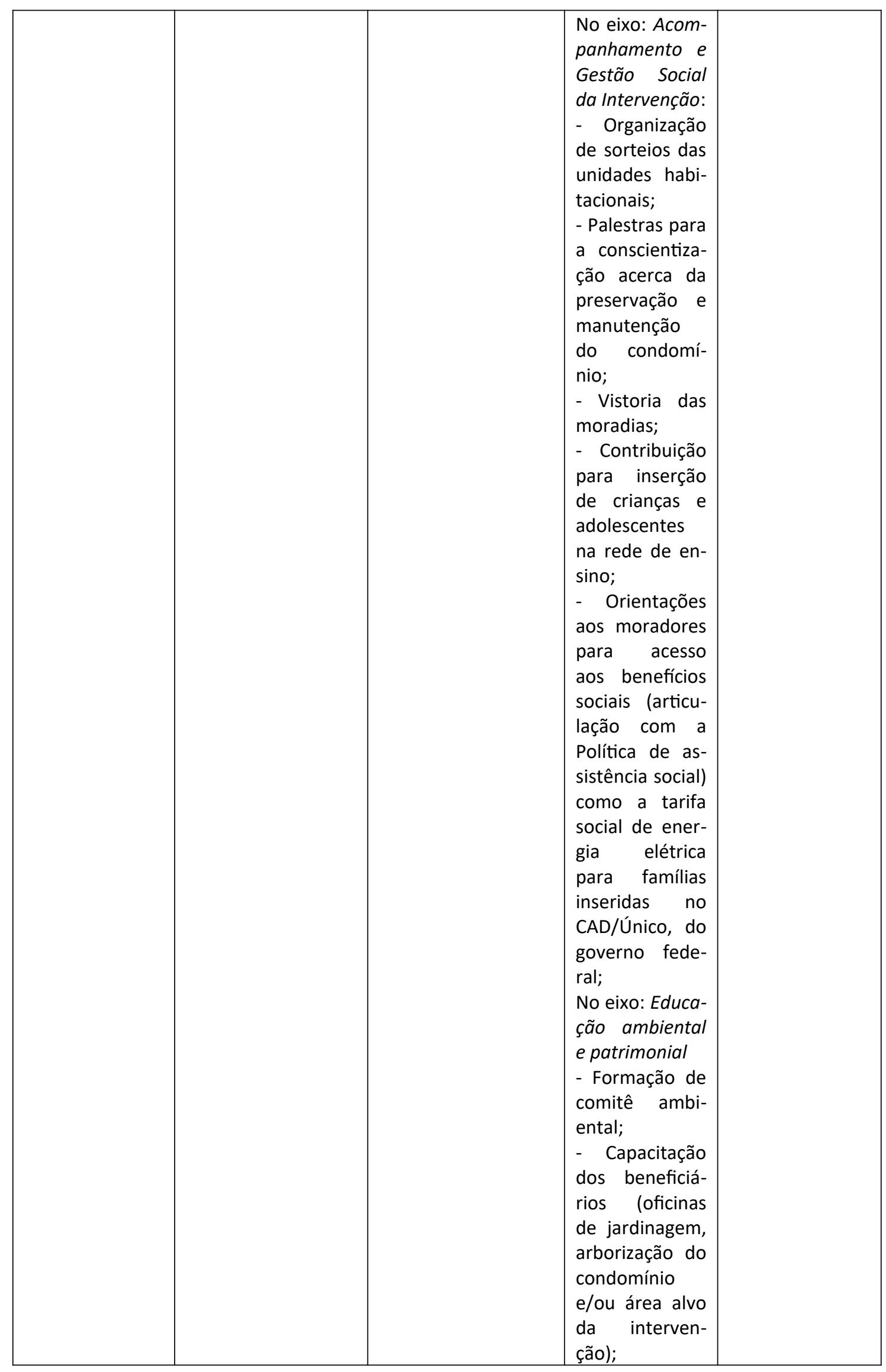




\begin{tabular}{|l|l|l|}
\hline & & - Palestras com \\
a temática de \\
meio ambien- \\
te. \\
No Eixo: Desen- \\
volvimento so- \\
cioeconômico: \\
- Cursos de for- \\
mação eapa- \\
citação profis- \\
sional (Exem- \\
plo: cursos de \\
marcenaria, ca- \\
beleireiro, es- \\
critório etc.) \\
(Santos, 2020).
\end{tabular}

Não é objetivo desse texto aprofundar o significado sócio-histórico do trabaIho da/o assistente social no Brasil, mas é possível identificar que em diferentes conjunturas históricas, a/o assistente social é requisitado - pela via das políticas urbanas e/ou habitacionais - a compor equipes técnicas para acompanhar a produção habitacional (obras físicas de construção de unidades habitacionais) e/ou urbanização de favelas/assentamentos precários, tendo em vista a necessidade do Estado em controlar a vida social dos moradores.

O Quadro 1, ainda que apresente sumariamente as requisições profissionais em diferentes conjunturas políticas, revela que em aproximadamente seis décadas, a grande maioria das requisições ao trabalho da/o assistente social esteve voltada ao acompanhamento da vida dos moradores com uma perspectiva de adequação ao novo espaço residencial, com práticas higienizadoras e controladoras, mediante o recurso da participação instrumental ${ }^{13}$ (Santana, 2011). Pode-se considerar que houve uma inflexão qualitativa nesse formato de requisição - ainda que frágil e limitada em sua potencialidade real pela própria condição da política social no capitalismo - no período após a Constituição de 1988, que abriu a possibilidade de alguns ganhos no interior da política urbana na década de 1990 e início do século XXI, onde foram incluídas nas demandas da política, intervenções urbanas, baseadas na participação democrática.

Percebe-se que as requisições às/aos profissionais são para a execução e formulação de projetos sociais no âmbito da política urbana/habitacional, o que se exige qualificação e reconhecimento amplo do campo das diferentes políticas públicas, tendo em vista a necessidade de articulação, pois a moradia envolve o acesso não apenas a casa, mas a uma série de serviços públicos que transversalizam

\footnotetext{
${ }^{13} \mathrm{Em}$ estudo sobre as orientações de participação social em projetos urbanísticos financiados pelo BID, Santana (2013, p. 110, grifos no original) afirma que: “A participação tem, assim, um caráter consultivo, não sendo, portanto, deliberativa. [...] a participação, nesta perspectiva, facilita a legitimidade dos programas e projetos por ele financiados, os quais têm [...] um enfoque setorizado e focalizado. Na mesma direção, esse tipo de participação garante o aceite da política, posto que desenvolve o sentimento de pertença das pessoas atendidas por determinado projeto; ao mesmo tempo em que garante que essas mesmas pessoas acompanhem/fiscalizem as atividades do poder público, com vistas alcançar a eficiência, a eficácia e a sustentabilidade dos projetos (...)".
} 
o direito à moradia tais como saúde, saneamento, educação, segurança pública, emprego e renda etc.

As respostas profissionais das equipes técnicas, onde se incluem as/os assistentes sociais, estão mergulhadas no conjunto das mediações contraditórias constitutivas das políticas urbanas e habitacionais, das desigualdades do acesso da classe trabalhadora à moradia adequada, da lógica mercantil do espaço urbano e inúmeras carências existentes nos territórios populares. Por sua vez, as respostas profissionais também estão carregadas de contradições - especialmente quando a/o profissional se orienta pelo denominado projeto ético-político do Serviço Social, visto que na relação entre as demandas de controle da vida social das/os moradoras/es também são desenvolvidas possibilidade de experiências de trabalho que incentivam a participação de base democrática.

Assim, na seção seguinte, vamos apresentar algumas possibilidades de como o fazer profissional da/o assistente social na política urbana e habitacional pode incorporar alguns instrumentais apresentados no Quadro 1, como potencialidade para contribuir na participação dos sujeitos nos diferentes territórios onde se insere a política.

\section{Reescrevendo a palavra (e o mundo): aprendizados para a formação profissional}

Que aprendizados do exercício profissional na área urbana e habitacional podem contribuir com a formação profissional em Serviço Social, destacando os instrumentais técnico operativos (constituintes da dimensão técnico-operativa) que, além de responder com competência teórico e técnica às requisições institucionais e profissionais, potencialize a participação dos moradores, estes que são sujeitos essenciais para as reivindicações políticas pelo direito à moradia e à cidade?

Antes de tudo é importante ratificar que a dimensão técnico-operativa não pode ser dissociada das dimensões teórico-metodológicas e ético-políticas na formação profissional, isto é, embora essa dimensão (técnico-operativa) tenha sua singularidade, ela não pode ser autonomizada das demais dimensões, para não cairmos no risco das práticas mágicas e conservadoras no trabalho profissional que valorizam, sobremaneira, a prática sem a teoria ${ }^{14}$. Santos $(2010$, p. 08$)$ afirma que a discussão dos instrumentos e técnicas requer que se façam as perguntas sobre "o que fazer?", o "para que fazer?", o "por que fazer?", e também "como fazer?".

A base da proposta deve levar sempre em conta a radical defesa dos interesses da classe trabalhadora, com atenção a todas as manifestações de dominação e de desrespeito às pessoas (crianças e adolescentes, mulheres, pretos e pretas, LGBTQIA+, idosos, indígenas, quilombolas, migrantes) que são mais

\footnotetext{
${ }^{14}$ Guerra (2010) chama a atenção para persistência no trabalho profissional do pensamento conservador materializado na presença do idealismo e do positivismo formal abstrato. No cotidiano profissional, dada a necessidade de respostas às situações concretas, muitas vezes os Assistentes Sociais acreditam que é possível prescindir dos elementos teóricos e ético-políticos. "Há aí uma ilusão metafísica de que basta a intencionalidade para se transformar uma realidade, uma identificação entre representação e teoria (conceito), entre desejo e possibilidade, do que resulta uma confusão de que é o pensamento que engendra a realidade (e não o contrário), inclusive na conviç̧ão de que na prática a teoria é outra ou simplesmente não existe" (p. 48).
} 
segregadas em sociedades de classe e, especialmente, na sociedade brasileira. Como relacionar esse princípio ao trabalho profissional na área da habitação e por quais instrumentos é possível desenvolver essas atividades como forma de estimular a participação social e a defesa de direitos?

- Nos plantões (atendimentos) sociais, visitas e processos de observação $\Rightarrow$ Elaborar instrumentais de registro de atendimento que condensem informações específicas sobre a população atendida, considerando a particularidade familiar, socioterriorial, socioeconômica, cultural, e as vulnerabilidades e potencialidades presentes naquele contexto;

=> Importante ficar atento à ocorrência de violação aos direitos humanos e estudar as pautas dos movimentos sociais (mulheres, negros, LGBTQIA+, indígenas, quilombolas, migrantes) e se aproprie das legislações existentes no país.

=> Na página do CFESS, há vários documentos que orientam sobre o exercício profissional (CFESS/ Manifesta, cartilhas etc.) - (http://www.cfess.org.br/).

- Com os dados obtidos no formulário de levantamento de demandas, onde se registra a situação das famílias para elaboração do cadastramento socioeconômico

=> Importante ter domínio das Instruções Normativas do Governo Federal, Estadual e municipal, conforme o caso;

$\Rightarrow$ Conhecer os protocolos técnicos e administrativos da instituição, e principalmente a rede de atendimento socioassistencial, organizações da Sociedade Civil, e demais políticas públicas e órgãos de defesa e garantia de direitos para facilitar a orientação e encaminhamento das demandas das famílias (educação, saúde, previdência e assistência social, dentre outras);

=> Desenvolver ações de cunho socioeducativo para a viabilização de acesso a informação e, sobretudo ao reconhecimento desses indivíduos e famílias enquanto cidadãs e cidadãos

No exercício profissional na área habitacional, a/o assistente social entra em contato com um número expressivo de pessoas, podendo assim contribuir com a organização comunitária de base democrática. Assim, torna-se importante a construção de estratégias que, no processo de execução das atividades definidas pelas instruções normativas, incluam conteúdos sobre direitos sociais, as contradições socioeconômicas da sociedade e direitos humanos. Por isso é importante o domínio teórico-metodológico e ético-político orientado pelo projeto profissional do Serviço Social.

- Na coordenação das reuniões com as famílias onde se repassam as informações sobre os projetos urbanísticos e para acompanhamento social => Os materiais/panfletos/cartazes podem ser utilizados como convites aos moradores;

=> Nas reuniões, as atividades grupais facilitam a participação e as discussões; 
$\Rightarrow$ Recursos audiovisuais (pequenos vídeos), materiais escritos (como cartilhas) acerca do conteúdo da reunião, contribuem para o interesse das/os moradoras/es sobre o assunto tratado;

$\Rightarrow$ A linguagem das/os técnicos (assistentes sociais, engenheiros civis e arquitetos e urbanistas) devem ser acessíveis as/os moradoras/es;

$\Rightarrow$ No momento de apresentação sobre os equipamentos urbanos previstos para o/a conjunto/residencial/obra, importante incluir pautas sobre direitos sociais e cidadania;

=> Painéis explicativos (fixos nas paredes) com informações sobre o projeto com livre acesso as/os moradoras/es são importantes no processo de participação.

- Nas atividades relativas à organização comunitária, educação ambiental e geração de renda

=> Importante o incentivo a formação de lideranças comunitárias e a identificação de organizações comunitárias já existentes no território onde se desenvolve o projeto para contribuir com a organização comunitária (exemplo: cursinhos populares, movimentos sociais);

=> Elaboração ou utilização de materiais socioeducativos (já produzidos) sobre direitos sociais, nível de desemprego no país, reformas (previdência, trabalhista), experiências concretas dos movimentos de resistência no país (mulheres, moradia, agroecologia, etc.), democracia e projetos alternativos de sociedade;

=> Vale a leitura do documento do CFESS: Atuação de assistentes sociais na Política Urbana: subsídios para reflexão. Brasília (DF), 2016. (http://www.cfess.org.br/arquivos/CFESS-SubsidiosPoliticaUrbana-Site.pdf).

Pode-se afirmar que no exercício profissional na área urbana, a/o assistente social realiza diversas atividades, mediante as quais é possível construir metodologias participativas; articular as políticas de forma intersetorial, sobretudo na construção de estratégias para acesso às políticas públicas; contribuir com acesso à moradia pela seleção dos beneficiários e com o acesso aos serviços urbanos em projetos urbanísticos; elaboração de diagnósticos socioeconômico e socioterritoriais; identificação das demandas imediatas dos indivíduos e famílias; assim como identificação dos equipamentos públicos de uso coletivo e os que estão faltando na área de intervenção urbanística.

Percebe-se a potencialidade no que concerne aos processos de participação social, podendo ser desenvolvido oficinas, reuniões com a temática da defesa da democracia e dos direitos sociais, dar ênfase ao protagonismo individual e coletivo. Os instrumentais são importantes ferramentas para a garantia de direitos, tais como a visita domiciliar e institucional, estudo de caso, reuniões planejadas. Outro campo de extrema relevância é realizar o planejamento junto aos beneficiários e/ou impactados por determinada política urbana/habitacional, viabilizando além do acesso à informação, a participação em todos os processos que envolvem a intervenção. Ressalta-se a importância do registro, sistematização das informações do cotidiano profissional, estabelecer estratégias que permitam a elaboração de relatórios de implementação e avaliação do impacto das ações na vida das/os 
trabalhadoras/es e, sobretudo, socializar junto à comunidade os resultados do trabalho.

Paz (2008, p. 253) afirma que o trabalho social deve contribuir com o acesso à cidade e aos serviços públicos, bem como com a participação social. A autora apresenta cinco aspectos sistematizados em experiências desenvolvidas por equipes de trabalho social, onde se inserem assistentes sociais:

a. o conhecimento do território e da população; b. preparação e capacitação da população; c. apropriação dos novos espaços e moradia; d. fortalecimento de processos coletivos, organização e gestão da vida em condomínio; e e. consolidação da nova condição de moradia.

Diante da identificação das dificuldades da relação teoria e prática, parece importante a construção de estratégias de ensino, pesquisa e extensão com vinculação orgânica com o trabalho da/o assistente social, apreendendo os entraves, as possibilidades, as contradições que permeiam o cotidiano dessas/es profissionais, que por sua vez possuem um lugar privilegiado, pois atuam no atendimento direto às mais diversas demandas das/os trabalhadoras/es.

Ao analisar os diferentes períodos históricos da inserção do Assistente Social nesse espaço sócio ocupacional, verifica-se a ocorrência de determinadas técnicas e instrumentos, tais como reuniões, entrevistas, seleção de demanda, plantões sociais, socialização de informação, assim pergunta-se o que mudou, se os instrumentais continuam os mesmos? Retoma-se a citação de Santos $(2010, p, 08)$ na qual afirma que é necessário que se façam as perguntas sobre "o que fazer", o "para que fazer", o "por que fazer", e "como fazer? Entende-se que se transformou o significado dessas técnicas e instrumentos, a intencionalidade, pois o projeto profissional do Serviço Social avança para a interpretação da realidade com vistas a transformá-la, a partir dos insumos da teoria social marxiana.

Importante neste contexto considerar a dimensão sociocultural, as particularidades dos indivíduos e famílias, por isso os instrumentos e técnicas não podem ser consideradas como receitas para o "fazer" profissional. Em uma sociedade fundada na desigualdade social, racial e de gênero é necessário um profissional criativo, qualificado, crítico e revolucionário para contribuir com as lutas políticas da sociedade na construção de outra sociabilidade, além do capital.

\section{Referências}

ABESS/CEDEPSS. Diretrizes gerais para o curso de Serviço Social (Com base no currículo mínimo aprovado em Assembleia Geral Extraordinária de 8 de novembro de 1996). Cadernos ABESS, n. 7. São Paulo: Cortez Editora, 1997. p. 58-76.

BRASIL. Ministério da Educação. Diretrizes Curriculares para os cursos de Serviço

Social. Resolução № 15, de 13 de março de 2002.

BRASIL. Instrução Normativa n. 8. Brasília, 2009. 
BRASIL. Portaria 21. Brasília, de 22 de janeiro de 2014. Brasília, 2014.

BRASIL. Portaria n. 464, de 25 de julho de 2018. Brasília, 2018.

FORTI, Valéria; GUERRA Yolanda. "Na prática a teoria é outra?”. In: FORTI, Valéria; GUERRA Yolanda. Serviço Social: Temas, Textos e Contextos. Coletânea Nova de Serviço Social. Rio de Janeiro: Lumen Juris, 2010.

GUERRA, Yolanda. A Dimensão técnico-operativa do exercício profissional. s.d. Disponível em: www.ts.ucr.ac.cr. Acesso em: 22 out. 2020.

GUERRA, Yolanda. Sobre a possibilidade histórica do projeto ético-político profissional: a apreciação crítica que se faz necessária. In: FORTI, Valéria; GUERRA Yolanda (Orgs.). Projeto Ético-Político do Serviço Social: contribuições à sua crítica. Coletânea Nova de Serviço Social. Rio de Janeiro: Lumen Juris, 2010.

MIOTO, R. C. T.; LIMA, T. C. S. A dimensão técnico-operativa do Serviço Social em foco: sistematização de um processo investigativo. Revista Textos \& Contextos Porto Alegre. v. 8 n.1 p. 22-48. jan./jun. 2009.

PAZ, Rosângela Dias Oliveira da; ARREGUI, Carola Carbajal; BLANCO, Marisa A.; RODRIGUES, Maria de Lourdes da Paz; TABOADA, Kleyd Junqueira. Trabalho social na política habitacional: percursos, lacunas e desafios. In: SANTANA, Joana Valente (Org.) Habitação e Serviço Social: dimensões teóricas, históricas e metodológicas. 1. ed. Campinas/SP: Editora Papel Social, 2018.

PAZ, Rosângela Dias Oliveira da. Intervenções urbanas e trabalho social. In: Carola Carbajal Arregui; Denise Neri Blanes (Orgs.) Metodologias do Trabalho Social. São Paulo: IEE/PUC-SP, 2008, p. 248-254.

PERDIGÃO, Ana Klaudia de Almeida Viana; SANTANA, Joana Valente. Produção habitacional e participação popular no reassentamento de famílias em Belém (PA). In: SANTANA, Joana Valente (Org.) Habitação e Serviço Social: dimensões teóricas, históricas e metodológicas. 1. ed. Campinas/SP: Editora Papel Social, 2018.

SANTANA, Joana Valente. Trabalho social em projetos de habitação: demandas e respostas sobre a participação comunitária (Belém-Brasil). Revista de Trabajo Social, FCH-UNCPBA, Tandil, ano 4, n. 6, 2011.

SANTANA, Joana Valente. Gestão de Cidades no Brasil: estratégias e orientações do Banco Interamericano de Desenvolvimento. 1. ed. Campinas/SP: Editora Papel Social, 2013.

SANTANA, Joana Valente. Habitação e direito à cidade: o trabalho do assistente social em tempos regressivos. In: Inez Stampa, Ana Lole, Márcia Botão, Nilza Rogéria Nunes (Orgs.). Trabalho, Regressão de Direitos e Serviço Social. Rio de Janeiro: Mórula Editorial, 2020a.

SANTANA, Joana Valente. Relatório Projeto de Pesquisa "Serviço Social e remoção de moradores atingidos por projetos urbanísticos no Brasil", 2020. Belém, Universidade Federal do Pará/UFPA, 2020b. 
SANTOS. Cláudia Mônica. Na prática a teoria é outra? Mitos e dilemas na relação entre teoria, prática, instrumentos e técnicas no Serviço Social. Rio de Janeiro: Editora Lumen Juris, 2010.

SANTOS, Cláudia Mônica dos. A dimensão técnico-operativa e os instrumentos e técnicas no Serviço Social. Revista Conexão Geraes, 2. semestre de 2013. p. 25-30.

SANTOS, Cláudia Mônica dos; NORONHA, Karine. O Estado da Arte sobre os Instrumentos e Técnicas na Intervenção Profissional do Assistente Social - uma Perspectiva Crítica. In: FORTI, Valéria; GUERRA Yolanda. Serviço Social: Temas, Textos e Contextos. Coletânea Nova de Serviço Social. Rio de Janeiro: Lumen Juris, 2010.

SANTOS, Rita de Cássia Barbosa dos. Trabalho Social: Discurso Contemporâneo na Política Habitacional Brasileira. In: SANTANA, Joana Valente (Org.) Habitação e Serviço Social: dimensões teóricas, históricas e metodológicas. 1. ed. Campinas/SP: Editora Papel Social, 2018.

SANTOS, Rita de Cássia Barbosa. Relatório de pesquisa "o Significado do Serviço Social: Requisições e Respostas Profissionais do Assistente Social na Política Habitacional". Belém, Universidade Federal do Pará/UFPA, 2020.

SARMENTO, Helder Boska de Moraes. Instrumental técnico e o Serviço Social. In: SANTOS, Cláudia Mônica dos. BACK, Sheila. GUERRA, Yolanda. (Orgs). A dimensão técnico operativa do Serviço Social: desafios contemporâneos. 3. ed. São Paulo. Cortez. 2017. 